\section{Origin of Amniotic Fluid Group-specific Component}

THE use of amniotic fluid for the prenatal diagnosis of genetic disease has prompted investigations into the origin of amniotic fluid protein. Several observations (refs. 1-5 and R. G. S. and D. J. H. B., manuscript in preparation) have suggested that the foetus contributes protein to the fluid early in pregnancy, and it has also been claimed that during this time amniotic fluid is an extension of the foetal extracellular space ${ }^{6,7}$. Conversely, in term amniotic fluid, the serum proteins transferrin and group-specific component $(\mathrm{Gc})$ have been found to be of maternal origin ${ }^{8-10}$. Serum proteins make up the great majority of amniotic fluid protein at all stages of gestation, but it is not known whether maternal or foetal serum is the source early in gestation. In this study, Gc polymorphism is used to investigate this point.

Polymorphism studies on Ge protein have shown that the protein in foetal serum is synthesized by the foetus from ten weeks of gestation onwards ${ }^{11}$. Thus, in cases where the foetal phenotype is discordant with the mother's, the amniotic fluid $\mathrm{Gc}$ would be concordant with the maternal phenotype if it is of maternal origin, but discordant if it is of foetal origin. In the latter case, the expected frequency of discordance between the foetal and maternal phenotypes is equal to the heterozygote frequency in the population ${ }^{12}$.

Antibody-antigen crossed electrophoresis (AACE) is known to show Gc as a heterogeneous protein ${ }^{13}$, but has not been previously used for Gc phenotyping. We used the method as it allows a detailed examination of the amniotic fluid Gc pattern without previous concentration of the fluid, and is sensitive enough to show small contributions from one or other allele. AACE was carried out using 1\% agarose and the buffer systems of Hirschfeld ${ }^{14}$. The first dimension was run at $6 \mathrm{~V} \mathrm{~cm}^{-1}$ for $3 \mathrm{~h}$, and the second dimension at $1.5 \mathrm{~V} \mathrm{~cm}^{-1}$ for more than $15 \mathrm{~h}$. The antiserum was raised in rabbits by subcutaneous injection of $\times 10$ concentrated amniotic fluid, which was dispersed in Freund's complete adjuvant for the first three injections. Amniotic fluid samples before 20 weeks of gestation were obtained at terminations of pregnancy, and thereafter at amniocentesis in cases of suspected rhesus isoimmunization. The Gc precipitate was identified in the gels by its characteristic heterogeneity ${ }^{13,14}$, and also by the use of a specific anti-Gc antiserum (Behringwerke).

Table 1 Concordance and Discordance for Maternal Gc Phenotype
Gestation (weeks)

$10-18$
$19-27$

28-38

\begin{tabular}{ccr}
\multicolumn{3}{c}{ Concordant pairs } \\
Maternal Gc phenotype \\
$1-1$ & $2-1$ & $2-2$ \\
11 & 8 & 2 \\
5 & 5 & 2 \\
14 & 8 & 1
\end{tabular}

Discordant pairs All phenotypes

0

0
Number of pairs studied in which concordance or discordance for Gc phenotype was found between the amniotic fluid and maternal serum, broken down according to gestational age and maternal $\mathrm{Gc}$ phenotype. Phenotype frequencies: $0.54 ; 0.38 ; 0.09$.

Table 1 shows that concordance of phenotype was found in all of the fifty-six maternal serum-amniotic fluid pairs studied. From the frequency of heterozygotes, approximately $38 \%$ discordance in at least one of the gestational groups would be expected if there were a major foetal contribution to the Gc of amniotic fluid. Among the cases summarized in Table 1 were eleven in which a sample of foetal serum was available for phenotyping. In four of these cases, discordance was found between the foetal and maternal phenotypes and, in each case, the phenotype of the amniotic fluid $\mathrm{Gc}$ was that of the mother.

From these results we conclude that throughout gestation the $\mathrm{Gc}$ in amniotic fluid is of maternal origin, and that it enters the fluid by passing through the placental or reflected membranes. This finding sounds a cautionary note for any attempts to carry out prenatal diagnoses of genetic disease either by direct screening of serum proteins or by linkage analysis using serum protein polymorphisms.

We thank Mrs R. M. Clayton and Dr C. Smith for help and advice, and Drs J. G. Robertson, J. Downie, J. M. Monaghan and G. Gordon for providing us with material. R. G. S. holds an MRC studentship. The work was supported by a grant from the Distillers Company Limited.

\section{R. G. SUTCLIFFE \\ D. J. H. BROCK}

University Department of Human Genetics,

Western General Hospital,

Edinburgh $\mathrm{EH} 42 \mathrm{HU}$

J. B. SCRIMGEOUR

Simpson Memorial Maternity Pavilion,

Lauriston Place,

Edinburgh EH3 9 EF

Received March 27; revised May 18, 1972.

${ }^{1}$ O'Brien, J. S., Okada, S., Fillerup, D. L., Veath, M. L., Adornato, B., Brennar, P. H., and Leroy, J. G., Science, 172, 61 (1971).

${ }^{2}$ Friedland, J., Perle, G., Saifer, A., Schneck, L., and Volk, B. W., Proc. Soc. Exp. Biol. Med., 136, 1297 (1971).

${ }^{3}$ Harper, P., Bias, W. B., Hutchinson, J. R., and McKusick, V. A., J. Med. Genet., 8, 438 (1971).

${ }^{4}$ Gitlin, D., and Boesman, M., J. Clin. Invest., 45, 1826 (1966).

5 Brzezinski, A., Sadovsky, E., and Shafrir, E., Amer. J. Obstet. Gynecol., 89, 488 (1964).

- Lind, T., Parkin, F. M., and Cheyne, G. A., J. Obstet. Gynaecol. Brit. Commonwealth, 76, 673 (1969).

7 Lind, T., and Hytten, F. E., Lancet, i, 1147 (1970).

8 Seppälä, M., Ruoslahti, E,, and Tallberg, T., Ann. Med. Exp. Fenn., 44, 61 (1965).

9 Ruoslahti, E., Tallberg, T., and Seppälä, M., Nature, 212, 841 (1966).

10 Usategui-Gomez, M., and Morgan, D. F., Nature, 212, 1600 (1966).

11 Melartin, L., Hirvonen, T., Kaarsalo, E., and Toinanan, P., Scand. J. Haematol., 3, 117 (1965).

12 Elandt-Johnson, R. C., Probability Models and Statistical Methods in Genetics, 132 (Wiley, New York, 1971).

13 Weeke, B., Scand. J. Clin. Lab. Invest., 25, 269 (1970).

14 Hirschfeld, J., Science Tools, 7, 18 (1960).

\section{New Antifertility Agent-an Orally Active Prostaglandin-ICI 74,205}

A MONTHLY application of contraception has the advantage that it involves application of medication only in the event of suspected pregnancy such as delayed menses ${ }^{1}$, thereby reducing the unnecessary exposure of healthy persons to drugs. An intravaginal application of prostaglandins (PGs) has been successfully used for this purpose in 11 women ${ }^{1}$. Naturally occurring PGs need to be administered in high doses to obtain termination of pregnancy by the oral route, however, and the effective doses have side effects such as vomiting, nausea and diarrhoea ${ }^{1}$. It would be desirable to develop an analogue of natural PG active orally in doses which have no undesirable side effects, and with this rationale in mind we developed a C-22 derivative (Fig. 1) of PGF 2 - -ICI 74,205 which appears to be some 20 times more potent orally than the parent PG in terminating early pregnancy in hamsters.

The antifertility properties were tested in pregnant hamsters as this species is known to be more sensitive to $\mathrm{PGF}_{2 \alpha}$ than rats $^{2}$. Adult hamsters were caged with fertile males at an appropriate stage of the oestrous cycle, and the day when spermatozoa were found in the vaginal smear was considered day 1 of pregnancy. Unless stated otherwise, all PGs were racemic. They were dissolved in phosphate buffer $(p \mathrm{H} \mathrm{7.4)}$ and administered either subcutaneously or orally once a day as indicated in Table 1. Animals were usually killed $48 \mathrm{~h}$ after 